\title{
Co existence of acute promyelocytic leukemia and autoimmune haemolytic anaemia in a girl - A diagnostic and therapeutic challenge
}

\author{
Jacob J.S. ${ }^{1}$, Suman F.R. ${ }^{2}$, Scott J.X. ${ }^{3}$, Latha MS ${ }^{4}$ \\ ${ }^{1}$ Dr Jerusha Samuela Jacob, Department of Pathology, ${ }^{2}$ Dr Febe Renjitha Suman, Department of Pathology, ${ }^{3}$ Dr Julius \\ Xavier Scott, Department of Pediatric hematology oncology, ${ }^{4}$ Dr MS Latha, Department of Pediatric hematology \\ oncology; all authors are affiliated with Sri Ramachandra Medical College and Research Institute, Chennai, Tamilnadu, \\ India
}

Address for Correspondence: Dr Febe Renjitha Suman, Email : febemd@gmail.com

\begin{abstract}
We describe a very rare case of paediatric female patient of acute promyelocytic leukemia (APL) with negative promyelocytic leukemia-retinoic acid receptor- $\alpha$ (PML- RAR $\alpha$ ) and normal karyotype co existing with autoimmune haemolytic anemia(AIHA) for the rarity, diagnostic and management challenges. The clinical outcome with arsenic trioxide (ATO) and all-trans- retinoic acid (ATRA) regime is good without relapse or residual disease with a close follow up of 6 months.
\end{abstract}

Key words: Promyelocytic leukemia, Autoimmune haemolytic anemia, Arsenic trioxide, All-trans- retinoic acid

\section{Background}

Acute myeloid leukemia (AML) represents $15 \%$ of pediatric leukemias, of which acute promyelocytic leukemia (APL) constitutes 4 to $11 \%$ [1]. Disseminated intravascular coagulation (DIC) is usually associated with this rare disease. A rare case of APL in a child presented as autoimmune hemolytic anemia (AIHA) which is usually an associated event in lymphoid neoplasms is being presented in view of the rare clinical presentation. Acute exacerbations of hemolytic process caused difficulty in diagnosis and treatment especially with blood products as supportive therapy. Though AIHA was reported with very few cases of acute myeloid leukemia, no case report is available about its coexistence with APML [2,3,4,5]. This case is reported in view of its rarity with respect to age group, clinical presentation, genetics and coexisting disease.

\section{Case Report}

One 11 year old female patient presented with fever on and off for the past 1 month. On examination she had pallor with hepatosplenomegaly. The patient had been well in the past. There is no family history of autoimmune disorders or malignant diseases.

Investigations: Laboratory examination showed normocytic normochromic anaemia with hemoglobin ofc $2.3 \mathrm{gms} / \mathrm{dl}$. Peripheral smear examination showed few spherocytes, leukocytosis (Total WBC count - 17000/c.mm) with $2 \%$ blasts and $12 \%$ promyelocytes (Figure 1). Thrombocytopenia (platelet count -0.3 lakhs/c.mm) was present. The biochemical parameters showed bilirubinemia and elevated lactate dehydrogenase. Direct Coombs test (DCT) was positive. Bone marrow aspirate (BMA) showed myeloid hyperplasia and increased number of promyelocytes with auer rods (Figure 2). Bone marrow trephine biopsy (BMB) showed erythroid hyperplasia and myeloid precursors which were myeloperoxidase (MPO) positive by immunohistochemistry (IHC). Flowcytometry done on BMA showed blasts positive for myeloid markers and negative for HLA DR, monocytic and lymphoid markers. CD56 and CD2 were also negative. A

Manuscript received: $04^{\text {th }}$ August 2016

Reviewed: $10^{\text {th }}$ August 2016

Author Corrected; $20^{\text {th }}$ August 2016

Accepted for Publication: 01 ${ }^{\text {st }}$ September 2016 
diagnosis of APL with AIHA was made. Fluorescence in situ hybridisation (FISH) and reverse transcriptase polymerase chain reaction (RT-PCR) for PML-RAR $\alpha$ was negative. Cytogenetics showed normal karyotype.

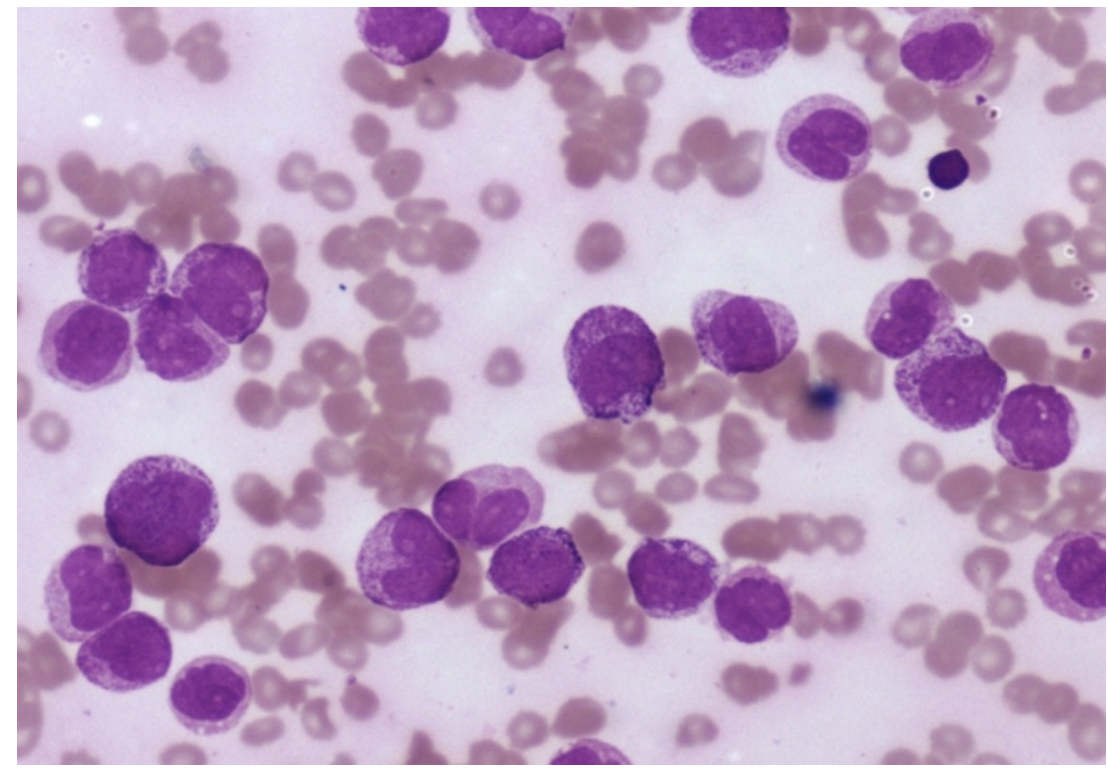

Figure-1: Peripheral smear, Leishman stain, $400 \mathrm{X}$

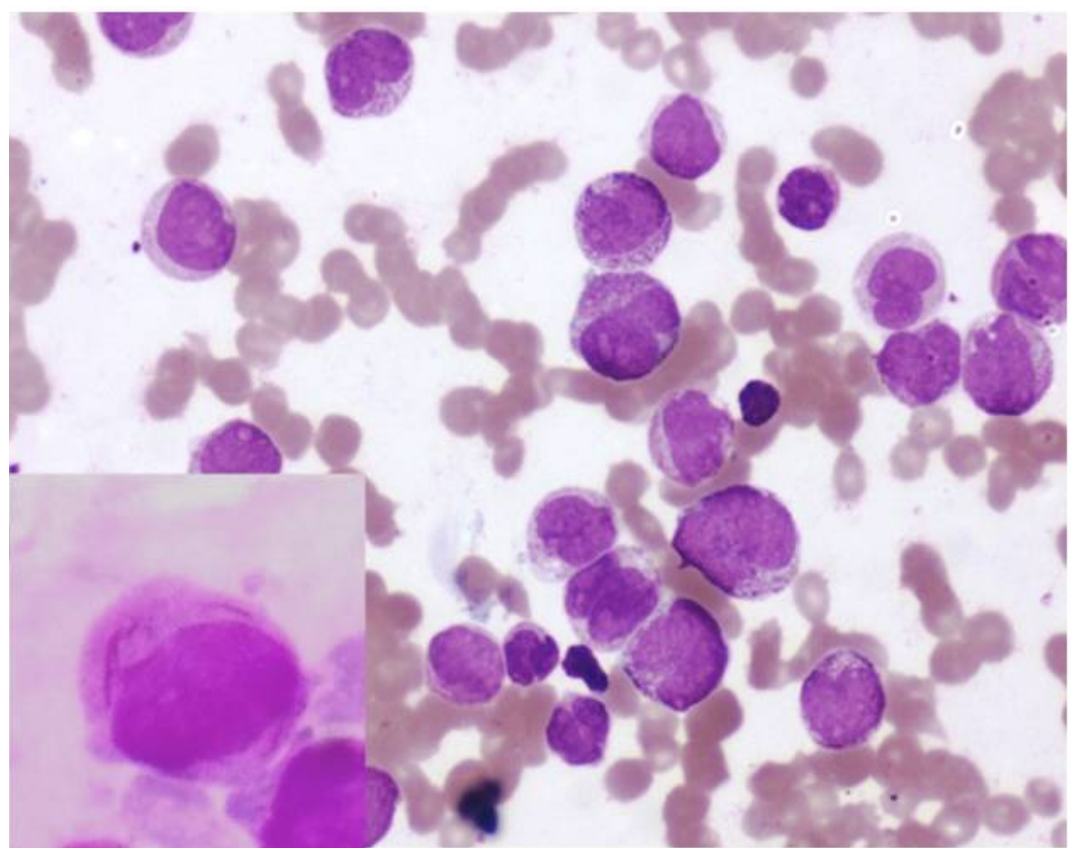

Figure-2: Bone marrow aspirate, Leishman stain, $400 \mathrm{X}$. Insert : Auer rods from a different area in the bone marow

Differential diagnosis: Acute myeloid leukemia (AML)- M2. By flowcytometry as the blasts were HLA DR negative this possibility is excluded as AML - M2 blasts are positive for HLA - DR

Treatment: The parents were counseled. She was started on arsenic trioxide (ATO) $0.15 \mathrm{mg} / \mathrm{kg}$ for 5 days $/$ week and alltrans-retinoic acid (ATRA) $10 \mathrm{mg}$ BD daily until she attained remission.

The patient was supported with least incompatible blood of the same group. The patient is continued with ATO 0.15 $\mathrm{mg} / \mathrm{kg}$ daily every alternate months and ATRA 10mg BD daily every alternate two weeks. Nutritional and hematinic support provided. 
Outcome: Peripheral smear after post induction chemotherapy did not show any promyelocyte or blast. BMA done at the end of post induction phase chemotherapy and after 3 months showed erythroid hyperplasia, maturation of the myeloid series and eosinophils. The clinical outcome has been good with close follow up of 6 months

\section{Discussion}

APL is a rare leukemia in pediatric age group representing $10 \%$ of all APML [6]. It is associated with PML-RAR $\alpha$ or its variants. In our patient PML-RAR $\alpha$ was not detected and karyotyping did not reveal other translocations.

Presence of cryptic arrangement is a possibility since the patient responded to ATRA as it had been reported all the rearrangements are ATRA sensitive except that with promyelocytic leukemia zinc finger - retinoic acid receptor $-\alpha$ (PLZF-RAR $\alpha$ ) [7]. The economic condition and unavailability had made molecular studies inaccessible, which if done might have located the rearrangement. The complications associated with APL are most commonly DIC. In our case co-existing AIHA was diagnosed. This is seen commonly in association with lympho-proliferative disorders [8].

There had been rare case reports of adult patients with AIHA associated with AM -M0, AML-M2 and chronic myeloid leukemia $[9,10]$. AIHA terminating as acute leukemia suspected of monocytic origin but not categorized had been reported in 196 3[11].

Aberrations in the immune regulatory mechanism might have allowed both an immune disorder and a leukemic process. Regarding the supportive measures to chemotherapy, AIHA poses difficulty in transfusion management.

\section{Conclusion}

APL occurring in a paediatric age group with negative PML- RAR $\alpha$ and normal karyotype is a rare condition. Coexisting AIHA makes the case more rare and first of its kind. Research on the probable cause of immune mechanism in the development of an autoimmune and a leukemic process need to be done in the future.

DCT must be done in all leukemic patients so that blood transfusion is carefully administered. Careful examination of peripheral smear and bone marrow is highly essential in hemolytic anemia to detect any coexisting leukemic process.

Funding: Nil, Conflict of interest: Nil

Permission from IRB: Yes

\section{References}

1. Gurney JG, Smith MA, Ross JA. Cancer among infants. Cancer incidence and survival among children and adolescents: United States SEER Program. 1975;1995:149-56.

2. Boccardi V, Papa G, Antonelli S, Girelli G, Liso V, Mandelli F. Autoimmune hemolytic anemia followed by myelomonocytic leukemia. Haematologica. 1977 Feb;62(1):88.

3. FRUMIN AM, KOHN A. Autoimmune hemolytic disease in acute leukemia. AMA archives of internal medicine. 1955 Feb 1;95(2):326-7.doi:10.1001/archinte.

4. PIROFSKY B. Autoimmune hemolytic anemia and neoplasia of the reticuloendothelium: with a hypothesis concerning etiologic relationships. Annals of internal medicine. 1968 Jan 1;68(1):109-21.doi:10.7326/00034819-68-1-109

5. Solal-Celigny P, Vazeux R, Vroclans M, Amar M, Herrera A, Bernard JF, Boivin P. Positive Coombs test in acute leukaemia. British journal of haematology. 1984 Aug 1;57(4):563-9. DOI: $10.1111 / j .1365-$ 2141.1984.tb02933.x

6. Nargund AR, Patil GV, Raghuram CP, Venkataswamy E. CD34 positive-microgranular variant of acute promyelocytic leukemia in a child. Indian Journal of Pathology and Microbiology. 2012 Oct 1;55(4):574. DOI: 10.4103/0377-4929.107828.

7. Yoo ES. Recent advances in the diagnosis and management of childhood acute promyelocytic leukemia. Korean J Pediatr. 2011 Mar;54(3):95-105. doi: 10.3345/kjp.2011.54.3.95. Epub 2011 Mar 31.

8. Chaudhary RK, Das SS. Autoimmune hemolytic anemia: From lab to bedside. Asian journal of transfusion science. 2014 Jan 1;8(1):5. DOI: 10.4103/0973-6247.126681.

9. Tamura H, Ogata K, Yokose N, et al.Autoimmune hemolytic anemia in patients with de novo acute 
myelocytic leukemia. Ann Hematol 1996;72:45-47. DOI: 10.1007/BF00663016.

10. Arbaje YM, Beltran G. Chronic myelogenous leukemia complicated by autoimmune hemolytic anemia. The American journal of medicine. $1990 \mathrm{Feb}$ 28;88(2):197-9.
11. Ben-Ishay D, Freund M, Groen JJ. A case of autoimmune hemolytic anemia with circulating cold agglutinins presenting for many years as" hypersplenism" and terminating in leukemia. Blood. 1963 Jul 1;22(1):100-8.

\section{How to cite this article?}

Jacob J.S. , Suman F.R., Scott J.X. ${ }^{3}$, Latha MS Co existence of acute promyelocytic leukemia and autoimmune haemolytic anaemia in a girl - A diagnostic and therapeutic challenge. Int J Pediatr Res.2016;3(8):640643.doi:10.17511/ijpr.2016.i08.15 